\title{
As máquinas de Queneau: por uma poética do código
}

Vinicius Carvalho Pereira (UFMT)

Recebido 31 jul. 2013/Aprovado 22 abr. 2014

\section{Resumo}

Uma das discussões centrais da Teoria da Literatura, independente da filiação teórica, é em que consiste o fenômeno literário: Intenção autoral? Interpretação do leitor? Construção conjunta de sentidos? Estas, entre tantas outras possíveis explicações, localizam a literatura como uma prática discursiva de sujeitos empíricos, mas podem ser questionadas em um contexto político, social e tecnológico que se afirma cada vez mais como "pós-humano". Nesse âmbito, uma poética oriunda da língua em si, como potência que devém ato na escrita - aqui entendida como acontecimento intransitivo -, apresenta-se como alternativa não só teórica, mas também na prática literária de autores como os do grupo francês Oulipo (Ouvroir de Littérature Potentielle). Diante de tal aporia - uma literatura que emerge do código, e não do sujeito -, este artigo analisa as obras de Raymond Queneau, fundador do Oulipo e autor de textos que se concebem como máquinas literárias, mais do que obras literárias. Entre estas, destacam-se aqui os livros Exercícios de estilo e Cent mille milliards de poèmes, os quais chamam atenção por apagar qualquer possível referencialidade dos textos. Estes funcionam por meio de engrenagens formais de fina engenharia, dotadas de uma significação intransitiva, a qual aponta continuamente para o código que azeita suas roldanas linguísticas $e$ as faz continuamente girar.

Palavras-chave: Oulipo; Raymond Queneau; máquinas literárias;poética do código. 


\section{Introdução}

Libertar a língua e a literatura por meio de regras restritivas: eis a tarefa paradoxal a que se lançou um grupo de escritores europeus na década de 60. A partir de travas formais autoimpostas à guisa de desafios, como a supressão de uma letra, o uso de determinado padrão métrico ou a reiteração de certos esquemas narrativos, os membros do Oulipo fizeram da atividade de escrita literária uma manifestação da própria linguagem, e não de um autor por meio dela.

Criado por Raymond Queneau, o OUvroir de LIttérature POtentielle vai de encontro às correntes do pensamento europeu na segunda metade do século XX, especialmente o existencialismo e o surrealismo. Em vez do absurdo, do nonsense, do místico ou do onírico, está em questão para os oulipianos uma escrita como acontecimento do código, procedimento maquínico determinado pelas formas textuais ou linguísticas, jogo em que as peças se movimentam segundo duras regras. Não seria, pois, um gênio autoral ou um sujeito preexistente que dotaria a linguagem de um sentido, mas sim ela mesma, a partir de seus algoritmos de associação ou exclusão, dos quais emergiria a significação.

Tal concepção da escrita está intimamente associada à noção de linguagem de que partem os autores oulipianos: em lugar da visão humanista da pragmática e da sociolinguística, é como estrutura pura e descarnada que os membros do Oulipo tratam a linguagem. Como eco de Saussure (1970), aos oulipianos a literatura interessa como langue, e não como parole, isto é, como potência e devir do sistema da língua, e não como obra singular, ou texto produzido por um sujeito. Segundo tal lógica, poética seria a língua, e não o poema em si. Para tanto, esses escritores optaram por valorizar a escrita como máquina cujas regras de funcionamento seriam definidas pelo próprio código, enquanto ao escritor caberia apenas assistir ao movimento das engrenagens.

Maquinador por trás da criação do próprio Oulipo, Raymond Queneau criou verdadeiros livros-objeto, máquinas poéticas que funcionam a partir de engenharias formais e arquiteturas verbais, as quais se analisam no presente artigo. Nessas obras, descentram-se as posições de sujeito autoral e sujeito leitor, colocando os mecanismos de combinação e seleção linguística como acontecimentos em série que operam a significação a despeito do referente e do sujeito: poéticas de um código maquínico. 


\section{Queneau e sua máquina de espelhos}

Entre os oulipianos, Raymond Queneau foi um dos que mais conquistaram prestígio para além dos círculos intelectuais e do meio acadêmico na França. Ex-membro do grupo de André Breton e do Collège de Pataphysique, além de fundador do Oulipo, Queneau foi um autor de produção diversificada em termos de gêneros (ensaios, poemas e romances) e estilos (do onirismo surrealista ao formalismo oulipiano), tendo muitas de suas obras sido rapidamente divulgadas e absorvidas no mercado europeu, graças, entre outros motivos, à sua atuação como editor da Gallimard.

Fascinado pelas Ciências Exatas ${ }^{1}$, Queneau não via muita diferença entre letras e números, senão como símbolos e traços que apontariam para algo mais além: o aliquid quo de todo signo. Prova disso são os Exercícios de estilo (QUENEAU, 1995), livro em que o narrador reconta de noventa e nove formas diferentes uma mesma história, valendo-se de operações matemático-linguísticas (permutações posicionais, comutações vocabulares isotópicas e associações sintáticas cambiantes) para chegar às distintas versões de uma mesma historieta:

No ônibus S, em hora de aperto. Um cara de 26 anos, chapéu mole com cordão em vez de fita, pescoço comprido demais, como se tivesse sido esticado. Sobe e desce gente. O cara discute com o vizinho. Acha que é espremido quando passam.

Tom choramingas, jeito de pirraça. Mal vê um lugar vago, corre para se aboletar.

Duas horas depois, vejo o mesmo cara pelo Paço de Roma, defronte à estação São Lázaro. Lá vai com outro que diz: "Você devia pôr mais um botão no sobretudo". Mostra onde (no decote) e como (para fechar) (QUENEAU, 1995, p.19)

Irrelevante em si o conteúdo da anedota, o que está em jogo nesses exercícios de estilo são as variações retóricas a cada reconto, como as praticadas nos ouvroirs rhétoriqueurs dos séculos XV e XVI. Não se trata, portanto, da forma como pano de fundo do enredo, mas exatamente o contrário: os diversos estilos que Queneau imprime a cada nova versão da história (entre gustativo, onomatopaico, botânico, anagramático, anglicista e tantos outros) funcionam como restrições formais, que determinam as operações em série da máquina linguística, retraduzindo noventa e nove meses um mesmo texto, segundo as especificidades lexicais e gramaticais dos mais diferentes discursos.

1 Autores oulipianos como Raymond Queneau, George Perec e Jacques Roubaud acreditavam que as Ciências Exatas poderiam oferecer novos modelos formais e desafios estruturais para a literatura.

Por conseguinte, a cada reconto esvazia-se progressivamente o conteúdo do texto, de modo que o leitor passa a olhar apenas para a materialidade dos signos, que perdem a dimensão referencial e ganham a de objetos gráficos vazios de sentido: engrenagens que servem apenas para fazer o código funcionar, mas sem uma mensagem a ser comunicada. 
Trata-se, assim, de textos repletos de espelhamentos recíprocos, ainda que leves irregularidades nas páginas-espelhos alterem a superfície significante do enredo comum, segundo os diferentes estilos que o autor se impõe. Sendo cada página um novo reflexo, distorcido, ampliado ou reduzido da anedota que serve de mote ao livro, Exercícios de estilo culmina em uma máquina narrativa, que produz em série novos textos, iguais mas diferentes, como os produtos de qualquer esteira de montagem. Ao narrador, cabe apenas o ofício de operador desse livro maquínico, ou papel-máquina (DERRIDA, 2004), conduzindo-o em suas performances e garantindo-lhe força performativa, na medida em que assegura a cada reconto um efeito de linguagem e de enunciação pura, apagando progressivamente o conteúdo da anedota repetida. Trata-se, pois, do livro de um escritor, e não de um autor, uma vez que é a tradutibilidade da escrita que garante a emergência dos textos, e não um caráter supostamente autoral dos mesmos.

Máquina de repetição e variação, Exercícios de estilo é uma caixa catóptrica, mecanismo formado por uma associação de espelhos cuja angulação causa a multiplicação da imagem do objeto encerrado na caixa. Como espelhos de parques de diversão, as superfícies refletoras da caixa catóptrica podem também não ser planas, o que adiciona à multiplicação das imagens sua distorção, tal qual se dá em cada exercício de estilo de Queneau.
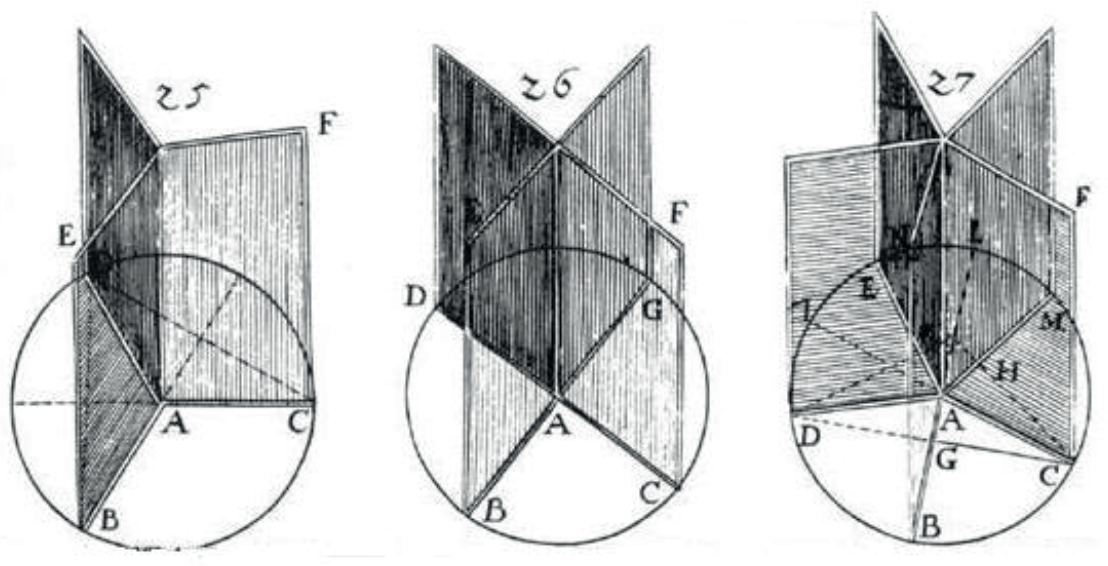

Figura 1: Aparato catóptrico com espelhos móveis

(BALTRUSAITIS, 1996, p.20).

Máquina de multiplicar e distorcer imagens, Exercícios de estilo replica uma mesma sequência imagética - as ocorrências banais com o narrador e o homem de chapéu - de tantas maneiras que se perde a noção de qual é o objeto e qual é o reflexo nos espelhos do livro. Assim, página a página, o encontro no ônibus, a altercação e a perda do botão do sobretudo deixam de contar alguma coisa e fixar uma origem da obra, de modo que a anedota não é ponto de partida, e sim eco cacofônico, eixo comum na série 
de variações em torno de um mesmo tema, atingindo o paroxismo de desaparecer no meio dos recontos.

De origem lábil, os exercícios passam a suceder-se, então, sem começo ou fim, podendo ser folheados aleatoriamente, sem perdas para a recepção do livro. Texto finito enquanto livro impresso, ilimitado enquanto jogo de espelhos em que começo e fim se perdem, Exercícios de estilo é, então, também um exercício de pensar o infinito, obsessão poética da matemática, mas também preocupação aritmética dos poetas.

O projeto literário de Queneau, matemático amador e poeta, tematiza, em diferentes obras, a impossibilidade de tanger a infinidade na literatura, como a própria quantidade de exercícios de estilo - 99 - revela. Quase cem, quase um número redondo, quase um quadrado, quase uma dezena de dezenas, o número 99 reflete essa impossibilidade de alcançar o todo, o limite, o fim ou a origem: só há cópias e pastiches em Exercícios de Estilo, mas não um verdadeiro infinito, uma vez que este sempre evade para um ponto mais além. Na obra circular, tal qual a disposição dos espelhos na caixa catóptrica, o último reconto poderia ser o primeiro, de modo que não faz sentido falar em início ou fim, original ou falsificação: os espelhos da máquina confundem o observador quanto aos objetos e imagens, de modo que tudo vira reflexo.

Sendo a catoptria um fenômeno geométrico da luz, não pode passar despercebido que uma das propostas de reescritura da historieta se intitula Geométrico, na qual os personagens e espaços do texto são descritos segundo proposições matemáticas e equações ou inequações, além da menção a sólidos e figuras planas.

Em um paralelepípedo retângulo que postularemos transporte, deslocando-se num plano euclidiano segundo a função retilínea $84 x+S=y$, um homoide $A$, definido por um segmento cilíndrico de seção $1>\sum_{i}^{n}=0 l i$, onde $l i$ indexa a média pescocínea da população homoide dada (...). Consideremos, agora, o encontro aleatório do homoide A com um homoide homólogo C (...). Determinar, agora, a nova topologia da fenda alterada segundo o postulado de $\mathrm{C}$ agindo sobre $\mathrm{A}$, em função da mínima razão conjunta $\mathrm{r}(\mathrm{A}+\mathrm{C}) \rightarrow 0$ (QUENEAU, 1995, p.132).

O que era afirmação na anedota, em frases declarativas, aqui dá lugar a um comando de cálculo para o leitor, como o que se encontra em questões matemáticas; o exercício de estilo vira, pois, exercício de matemática, em toda a ambiguidade que essa expressão encerra. Ler, então, devém calcular, decifrar e encontrar, em um imperativo de combinar variáveis e chegar a soluções. Contudo, tal como é impossível realizar algum cálculo com os parcos dados oferecidos pelo exercício de estilo Geométrico, também uma interpretação final ou metafísica, como origem ou fim, de significados únicos e teleológicos, perde-se nesse livro.

Trata-se de uma geometria de simulacros e reflexos enganosos, como as palavras que ludibriam o homem quanto ao 
mundo - fantasmagorias de um real que lhes escapa -, ou como os exercícios de estilo que se sucedem em uma voragem que engole aquilo mesmo que é estilizado: a narração. Visto que esta é tradicionalmente caracterizada como sucessão de mudanças e ações que recaem sobre uma ou mais personagens ao longo do tempo (CUDDON, 1998), um livro de reflexos e repetições do enredo sacrifica sua narratividade e deixa de falar sobre o mundo ou um conjunto de personagens, para falar apenas sobre si mesmo e a intransitividade da linguagem.

Máquina de contos especulares, Exercícios de Estilo é espelho da própria linguagem, consagrando uma máxima que permeia muitos dos outros livros de Queneau: a de que toda variação é, no fundo, repetição. Como engrenagem que roda incessantemente sobre si mesma, o jogo a que se lançam o autor e o leitor desse livro prevê uma mudança na enunciação de cada história, a qual redunda, porém, em um eterno retorno ao mesmo ponto.

Não há incompatibilidade entre a repetição e a novidade do que difere. Falando de modo alusivo e elíptico, uma diferença sempre faz com que a repetição se desvie. Chamo isso de iterabilidade, o surgimento do outro (itara) na reiteração (DERRIDA, 2004, p.331).

Programática, no fundo toda máquina sempre repete um mesmo grupo de procedimentos ou algoritmos, ainda que sob uma aparência de novidade. A iteração da historieta, como os repetitivos movimentos de um autômato ou o folhear ritmado das páginas do livro, funde o já visto e o não visto, tal qual o Unheimlich (FREUD, 1969) do homem que se olha no espelho, ou do leitor que se defronta com os exercícios catóptricos de estilo e percebe um enredo conhecido materializado sucessivamente de maneiras diversas.

No entanto, esse autômato narrativo que deveria recontar ininterruptamente uma mesma história, com variações no plano da enunciação, esbarra em um arbitrário número 99, em que malogra sua infinitude. Sempre haveria mais um exercício de estilo a ser escrito, mais um reflexo que as superfícies refletoras da caixa poderiam produzir.

A máquina é, então, um fracassado sonho megalomaníaco, que tudo promete, mas trinca sempre em uma engrenagem mal azeitada, um erro de programação, uma limitação da linguagem: o todo escapa por entre os encaixes do dispositivo. Nesse sentido, se Exercícios de Estilo é uma tentativa de recontar de todas as formas possíveis uma história, mas esbarra justamente na incompletude do projeto, esse livro pode ser entendido como uma grande metáfora do ato da escrita. Escrever é, desde sempre, um desvario do autor que tenta captar o infinito universo em uma folha de papel, mas se descobre como apenas mais um efeito de significação produzido pela cadeia significante (LACAN, 1964). 
Na máquina catóptrica, em que imagens e objetos se refletem e confundem, perdem-se também o sujeito e a voz autoral, que se dissipa em eco que reverbera na caixa de espelhos.

Os próprios desafios formais ao gosto oulipiano, como as noventa e nove reescrituras da mesma anedota, podem ser entendidos como máquinas literárias capazes de produzir novos textos ou mesmo revificar restrições inerentes ao idioma, como máquinas escritas que alimentassem a si mesmas - realização do sonho renascentista do moto contínuo. Sendo essas restrições formais antes de tudo travas linguísticas, é ao caráter mecânico também da língua que estas devem sua maquinicidade:

A máquina é como a gramática de um texto, quando isolada de sua retórica, o elemento meramente formal sem o qual nenhum texto pode ser gerado. Não pode haver nenhum uso da linguagem que não seja, dentro de uma certa perspectiva, assim radicalmente formal, ou seja, mecânico, não importa a que nível de profundidade esse aspecto possa ser ocultado por ilusões estéticas e formalistas (MAN, 1996, p.328).

Sendo a gramática uma máquina, as máquinas poéticas de Queneau, como Exercícios de Estilo, ou Cent mille milliards de poèmes (analisado na próxima seção deste artigo), não podem prescindir da língua e, portanto, passam pelo imperativo de que o inconsciente, como linguagem, é máquina que produz texto, poesia, desejo: máquina desejante (DELEUZE; GUATTARI, 2010), enfim.

As máquinas desejantes são máquinas binárias, com regra binária ou regime associativo; sempre uma máquina acoplada a outra. A síntese produtiva, a produção de produção, tem uma forma conectiva: "e", "e depois"... É que há sempre uma máquina produtora de um fluxo, e uma outra que lhe está conectada, operando um corte, uma extração de fluxo (o seio - a boca). E como a primeira, por sua vez, está conectada a uma outra relativamente à qual se comporta como corte ou extração, a série binária é linear em todas as direções. O desejo não para de efetuar o acoplamento de fluxos contínuos e de objetos parciais essencialmente fragmentários e fragmentados. O desejo faz correr, flui e corta (DELEUZE; GUATTARI, 2010, p.17).

\section{Queneau e sua máquina de calcular}

Em 1961, Queneau deu um passo ainda mais radical na composição de suas máquinas literárias, publicando Cent mille milliards de poèmes, livro que habita a fronteira entre o literário e o mecânico, inclusive na forma de produção e recepção da obra. Literatura potencial, o livro tem potência de motor de grande porte, a qual se revela exponencialmente - na ordem de grandeza de $10^{14}$ - já em seu título.

A meio caminho entre o livro e a máquina, inclusive no que diz respeito à encadernação e à forma de manuseio e leitura da obra, Cent mille milliards de poèmes surpreendeu os leitores de seu 
tempo e ainda o faz hoje em dia, na medida em que contradiz a característica mais fundamental do que se entende frequentemente como livro impresso: a ordenação de páginas sequenciais, acessíveis uma de cada vez pelo ato de folhear com os dedos. Em vez dessa estrutura, o dispositivo literário de Queneau conta com um sofisticado sistema de engrenagens menores de papel, que se movem de forma coordenada.

A um primeiro olhar, o livro do poeta francês é composto por apenas dez páginas, havendo em cada uma delas um soneto, o que não o distinguiria de qualquer outra compilação de textos escritos com essa forma fixa. Trata-se, aliás, de dez sonetos bem simples do ponto de vista do conteúdo, contemplando clichês temáticos como, respectivamente, as paragens exóticas, a arte grega, o cotidiano litorâneo, a desigualdade social, a passagem do tempo, a saudade do campo, o duplo, o papel da poesia, os prazeres da mesa, a morte.

Ao passo que as imagens presentes nesses poemas podem ser vistas como lugares-comuns, o que torna o livro uma máquina literária única é o fato de que cada uma de suas páginas está cortada em quatorze tiras horizontais de papel, havendo apenas um verso em cada filete, como se vê na figura a seguir.

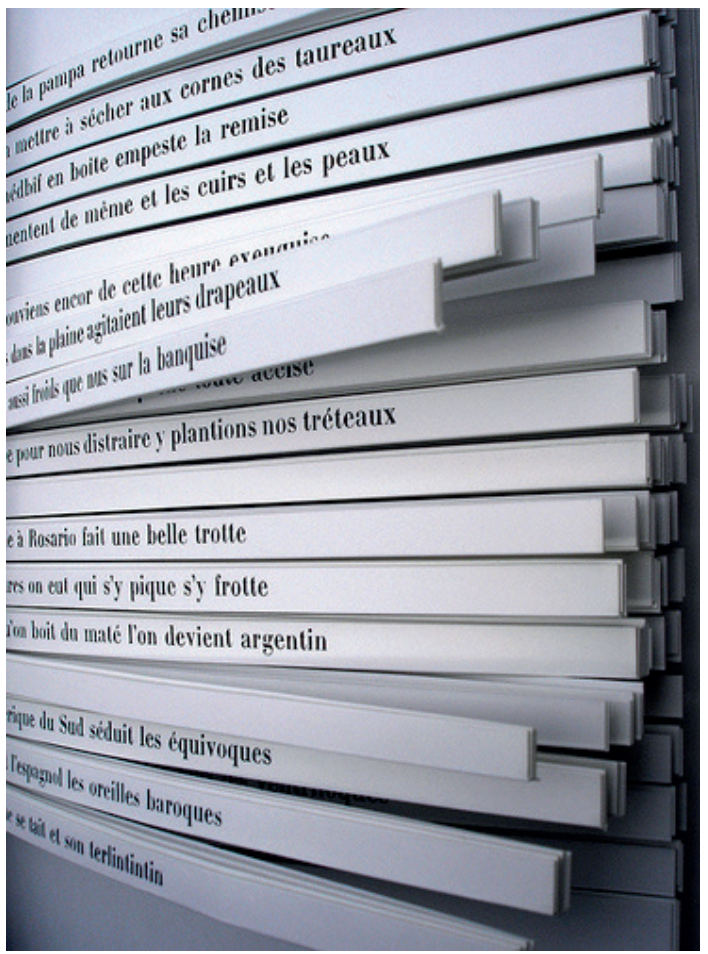

Figura 2: Cent mille milliards de poèmes

Totalizando cento e quarenta tiras, organizadas em quatorze pilhas de dez graças à encadernação do livro, esses filetes podem ser aleatoriamente folheados, juntando um verso de um soneto, outro do segundo e assim por diante, a fim de formar um novo 
soneto conforme o desejo do leitor, como nos livrinhos infantis de pano em que se unem a cabeça de um animal, o tronco de outro e os pés de um terceiro.

Lúdica como esses minibestiários para crianças, a obra se revela um inteligente jogo com a língua e com a forma fixa poética mais prestigiada no mundo ocidental, pois qualquer combinação de seus versos forma um soneto coerente e fiel às regras da versificação, inclusive no que diz respeito ao ritmo, à rima e outros fenômenos de sonoridade.

Foi mais inspirado pelo livro infantil intitulado Têtes de Rechange que pelos jogos surrealistas do gênero Cadavre exquis que concebi - e realizei - esta pequena obra que permite a cada pessoa compor à vontade cem trilhões de sonetos, todos regulares, bem entendido. Trata-se de um tipo de máquina para fabricar poemas, mas em número limitado; porém, é verdade que esse número, embora finito, fornece uma leitura para quase cem milhões de anos (lendo vinte e quatro horas por dia) (QUENEAU, 1961, p.2, trad. livre).

Essa fala de Queneau, além de revelar a influência dos supracitados livros infantis na composição de sua obra, denota que é literal o título Cent mille milliards de poèmes, o qual expressa a quantidade de poemas diferentes que as distintas seleções de versos podem gerar: $10^{14}$ (100.000.000.000.000), ou cem trilhões de sonetos, uma vez que cada um dos quatorze versos do soneto italiano pode ser preenchido por dez tirinhas diferentes nessa obra. Obviamente, trata-se de um número apenas potencial, pois, apesar de a quantidade de sonetos gerada realmente chegar a essa cifra astronômica, ser humano algum será capaz de ler todos, como o poeta prova, por cálculos matemáticos no prefácio.

Considerando $45 \mathrm{~s}$ para ler um soneto e 15 s para trocar os filetes, 8 horas por dia, 200 dias por ano, tem-se para mais de um milhão de séculos de leitura; lendo o dia todo, 365 dias por ano, têm-se 190.258.751 anos mais uns quebrados (sem levar em conta os anos bissextos e outros detalhes) (QUENEAU, 1961, s/p, trad. livre).

Desse modo, a leitura de Cent mille milliards de poèmes esgota o tempo humano, incipiente para apreciar todas as suas nuances, $\mathrm{o}$ que relembra a célebre frase de Turing, usada como epígrafe neste artigo: "Apenas uma máquina pode apreciar um soneto escrito por outra máquina", haja vista a aparente infinitude - aos finitos olhos humanos - contida nessa cifra incontável.

Aristóteles, ao falar sobre o infinito, entendia-o apenas como ficção humana, verossímil, mas não verdadeira, como potência que não devém ato, já que, para o estagirita, no real nada pode ser infinito, apenas parecendo como tal diante da insuficiência dos olhos humanos (SILVA, 2007, p.45). Assim, todo número demasiado grande, a que um homem jamais chegaria contando, poderia ser 
tomado como potencialmente infinito na visão aristotélica, revisitada no projeto de literatura - também potencial - de Queneau.

Finitude infinita, o livro do poeta francês se revela, pois, uma máquina de papel - ceci n'est pas un livre - que gera sonetos a partir de um simples algoritmo de combinatória, o qual, graças ao engenho morfossintático e semântico, redunda em um texto que faz sentido (e sempre outro sentido, graças aos deslizamentos dos elementos coesivos), recombinando versos do seu banco de dados. Para o sucesso dessa empreitada, o autor esmerou-se no desafio a que se propôs, conforme afirma no prólogo do livro, garantindo: que as dez opções de cada pilha para cada verso do soneto fossem isossintáticas, que todos os versos fossem alexandrinos perfeitos, que não houvesse repetição de palavras, que todas as concordâncias - verbais e nominais - obedecessem à norma culta, que os versos fossem relacionados por parataxe e hipotaxe etc.

Ademais, cada novo soneto produzido - um entre 100.000.000.000.000 possíveis - estimularia a curiosidade do leitor a mais uma folheada, mais uma combinação, mais um teste da eficácia da máquina. Como o fluxo entre as binárias máquinas desejantes, operando tanto no eixo sintagmático (da relação entre versos) como no paradigmático (da seleção dos versos), as engrenagens do dispositivo literário de Queneau exigem, a cada leitura, uma nova rotação ou combinação. Seus filetes recortados de páginas são, diria Derrida (2004), efeito de corte e causa de corte: o que esses objetos parciais cortam e refluem entre si na dinâmica do desejo não são só os versos dispersos nos filetes do livro, produto da cesura à tesoura ou guilhotina, mas ainda os próprios sonetos que estes geram a partir dos cortes, na medida em que são também apenas fragmentos de um todo maior e instável - o livro-máquina.

Tal instabilidade nega, inclusive, uma das características mais primordiais na definição do objeto livro, que é seu imobilismo (DERRIDA, 2004), sua condição de fiel depositário de informações, a ser consultado e usado mesmo como prova, quando necessário, contra a mobilidade e a efemeridade da palavra oral.

Essa aparente infinidade de textos contidos em um mesmo livro, ficção que o oulipiano sans savoir Borges revisita em uma série de contos fantásticos, como a "Biblioteca de Babel" (1989) ou o "Livro de areia" (1989), faz de Cent mille milliards de poèmes não só uma obra de arte, mas também a realização de uma promessa imemorial, em que o homem, por meio da linguagem, roçaria as fronteiras do absoluto.

Nessa tentativa de atingir o absoluto - torre, biblioteca, ou mesmo um livro de Babel -, ouvem-se as reflexões de Derrida acerca da escrita e sua força, como violência contra toda forma de significação estável ou tradicional. Para ele, a escritura 
é o momento em que é preciso decidir se vamos gravar o que ouvimos. E se gravar salva ou perde a palavra. Deus, o Deus de Leibniz, [...] não conhecia a angústia da escolha entre os possíveis: era em ato que pensava os possíveis e dispunha deles como tal no seu Entendimento ou Logos; é o "melhor" que, em todos os casos, favorece a estreiteza de uma passagem que é Vontade. E cada existência continua a "exprimir" a totalidade do Universo. Aqui não há portanto tragédia do livro. Há apenas um Livro e é o mesmo Livro que se distribui por todos os livros (DERRIDA, 2009, p.11).

Se é a escrita o momento de decidir se salvamos ou perdemos a palavra, Cent mille milliards de poèmes é, então, uma tentativa malfadada de superar essa aporia da linguagem, abarcando todos os sonetos possíveis, todos os livros dentro do seu livro, em lugar do Livro leibniziano distribuído por todos os livros. Assim, Prometeu imitando deuses mitológicos, criando criaturas criadoras, Queneau produz um livro que se confunde com a ideia leibniziana de Deus, o qual conteria virtualmente infinitas leituras e, portanto, tentaria conter todos os livros. No entanto, como toda tentativa de roubo do fogo divino redunda em fracasso nas mais diversas mitologias, a obra do poeta francês é apenas quase infinita: 100.000.000.000.000 sonetos, apesar de formarem um número muito grande, ainda podem ser contados e superados pela mera adição de uma unidade, de forma que haverá sempre um soneto que escape ao megalômano livro poeta.

Repensando o conceito de literatura e de arte, não só como carpintaria verbal, mas como tékhne, palavra devolvida à sua origem ambígua entre tecnologia e arte, o livro de Queneau se mostra uma materialização de sonhos humanos que permeiam todas as épocas e culturas, como a quimera do texto que se abre em novos textos, movimento hipertextual sempre infinito, tal qual a língua que jamais deixa de soar e sobrevive à morte do sujeito. Máquina de papel, Cent mille milliards de poèmes revela-se, então, arte não só na trama dos textos que enseja, mas na possibilidade mesmo de ensejá-los, independente da vontade do autor, o qual sequer conhece todos os sonetos que seu livro pode gerar. Nesse sentido, o livro como máquina desejante e poemática se apresenta como materialização da ideia de que o texto é sempre produto da própria imanência da linguagem, e não de um sujeito a priori.

Cotejando a matriz interna de combinatória que funda Cent mille milliards de poèmes e os sonetos por ela produzidos, pode-se ter uma ideia mais clara de como essa obra - contingente de tantas outras - funciona: desmontamos, então, a máquina, a fim de ver como giram suas engrenagens. Para tanto, parta-se do soneto formado pela sétima opção de verso de cada uma das quatorze pilhas de filetes:

Quand l'un avecque l'autre aussitôt sympathise se faire il pourrait bien que ce soit des jumeaux 
Et pourtant c'était lui le frère de feintise qui clochard devenant jetait ses oripeaux un frère même bas est la part indécise que les parents féconds offrent aux purs berceaux

Le généalogiste observe leur bouillotte gratter le parchemin deviendra sa marotte il voudra retrouver le germe adultérin

Frère je te comprends si parfois tu débloques frère je t'absoudrai si tu m'emberlucoques la gémellité vraie accuse son destin ${ }^{2}$.(QUENEAU, 1961, s/p)

Representado esquematicamente em uma matriz $314 \times 10$, tal como um computador o registraria em seu sistema, esse soneto obedeceria ao seguinte esquema combinatório:

2 Dada a estrutura de Cent mille milliards de poémes, decidiu-se não traduzir aqui os sonetos, pois isso implicaria a perda dos encaixes entre versos quando de sua permuta.

3 Afeito ao caráter matricial da linguagem, Queneau crê que não só seu livro, mas mesmo a gramática da linguagem cotidiana se reja por multiplicações de matrizes. Para ele, a formação de frases se daria pelo produto de duas matrizes, em que uma seria composta por termos gramaticais (pronomes, artigos, preposições etc.) e outra por termos lexicais (verbos, substantivos, adjetivos e advérbios de modo) (QUENEAU, 1970).

$$
Q=\left(\begin{array}{llllllllll}
0 & 0 & 0 & 0 & 0 & 0 & 1 & 0 & 0 & 0 \\
0 & 0 & 0 & 0 & 0 & 0 & 1 & 0 & 0 & 0 \\
0 & 0 & 0 & 0 & 0 & 0 & 1 & 0 & 0 & 0 \\
0 & 0 & 0 & 0 & 0 & 0 & 1 & 0 & 0 & 0 \\
0 & 0 & 0 & 0 & 0 & 0 & 1 & 0 & 0 & 0 \\
0 & 0 & 0 & 0 & 0 & 0 & 1 & 0 & 0 & 0 \\
0 & 0 & 0 & 0 & 0 & 0 & 1 & 0 & 0 & 0 \\
0 & 0 & 0 & 0 & 0 & 0 & 1 & 0 & 0 & 0 \\
0 & 0 & 0 & 0 & 0 & 0 & 1 & 0 & 0 & 0 \\
0 & 0 & 0 & 0 & 0 & 0 & 1 & 0 & 0 & 0 \\
0 & 0 & 0 & 0 & 0 & 0 & 1 & 0 & 0 & 0 \\
0 & 0 & 0 & 0 & 0 & 0 & 1 & 0 & 0 & 0 \\
0 & 0 & 0 & 0 & 0 & 0 & 1 & 0 & 0 & 0 \\
0 & 0 & 0 & 0 & 0 & 0 & 1 & 0 & 0 & 0
\end{array}\right)
$$

Adota-se aqui a tradicional notação matricial de que 0 indica o não preenchimento, ou o não uso de determinado filete, ao passo que 1 denota o uso do verso desse filete na composição do soneto. Máquina de sistema binário, a língua, tal qual Cent mille milliards de poèmes, também opera por meio de relações opositivas, segundo a compreensão estruturalista da organização do código em dicotomias, como ficou consagrado a partir da noção saussuriana de valor linguístico (SAUSSURE, 1970). Tal estruturação do sistema linguístico como uma série de díades, zero e um na linguagem computacional (que correspondem à ausência e à presença de carga elétrica), confirma a analogia entre a linguagem humana, os algoritmos computacionais e o funcionamento da máquina de 
Queneau, corroborando a leitura de seu livro como uma máquina de calcular, escrever e versejar.

Ademais, adotando como padrão matemático que as filas verticais sejam chamadas de colunas e as horizontais sejam denominadas linhas, pode-se dizer que as quatorze linhas dessa matriz correspondem aos espaços potenciais dos quatorze versos de qualquer soneto montado no livro; por sua vez, as dez colunas representam a dezena de possibilidades de preenchimento para cada um desses espaços. Nota-se, assim, uma solidariedade sintagmática entre as linhas (relação in praesentia) na composição dos sonetos, em paralelo a uma organização paradigmática das colunas, que se podem substituir sucessivamente, mas nunca figurar ao mesmo tempo (relação in absentia), na potencialidade das diversas formações poemáticas.

Observe-se, ainda, que apenas a sétima coluna foi preenchida pelo algarismo 1, mostrando que em todas as 14 linhas, isto é, em todos os 14 versos do soneto, utilizou-se apenas a sétima opção oferecida pela máquina de Queneau, culminando no soneto anteriormente citado.

Este, por sua vez, retoma no plano do conteúdo a catoptria de Exercícios de Estilo e as variações contínuas dos sonetos de Cent mille milliards de poèmes, as quais, porém, mantêm relação dialética com a reiteração. Iguais e diferentes, próximos e distantes: essa é a cisão que sofrem os sonetos do livro, no corte entre os filetes, e os gêmeos de que fala o poema, cindidos também no corte do cordão umbilical e da placenta.

Livro-máquina de estrutura matricial, seus sonetos são filhos da mesma matriz uterina (derivado de mater, mãe) e algébrica, como os gêmeos até então unidos no tempo e no espaço ("quand l'un avec l'autre aussitôt sympathise") que sofrem um trauma: la découverte. Découvrir um segredo, découvrir um livro, é sempre retirar uma couverture, cobertura ou capa, da história de dois irmãos ou dois sonetos, unidades que devêm pares a partir de um corte primeiro e traumático.

La découverte voilà qui traumatise é, pois, o primeiro corte, castração do cordão umbilical que instaura o sujeito no universo da incompletude, da labilidade, da errância. Antes dissolvido na unidade e na completude do corpo materno, o não eu, a não falta, os $10^{14}$ sonetos, virtualmente infinitos, têm de se tornar um só, a partir da cisão entre seus filetes e a fixação de apenas 14 deles. Como os gêmeos, cuja gémellité vraie accuse son destin, todos os sonetos do livro têm uma origem comum, a qual se distancia no corte e está sujeita a descaminhos díspares.

Se um dos irmãos vira príncipe e o outro mendigo (et pourtant c'était lui le frère de feintise/ qui clochard devenant jetait sés oripeaux), o mesmo fado aguarda os poemas da máquina, uma vez que alguns deles podem ser primores estéticos, enquanto outros apenas golens mal encaixados. O leitor, porém, qual o médico que 
observe leur bouillotte, a fim de compreender o mistério da gênese dos duplos, também tem sua sina definida pela máquina: gratter le parchemin deviendra sa marotte. Escalavrando o pergaminho, ou folheando incessantemente a matriz da máquina, o leitor busca mais rebentos da parturiente, sonetos gêmeos nascidos do palimpsesto mecânico.

Basta, então, folhear o livro, ou reordenar a matriz matemática, com vistas a encontrar mais um gêmeo do soneto, a fim de perscrutar-lhe no corpo o que seus cortes, fissuras e orifícios entre versos escondem.

Quand l'un avecque l'autre aussitôt sympathise

se faire il pourrait bien que ce soit des jumeaux

la découverte alors voilà qui traumatise

on espère toujours être de vrais normaux

L'un et l'autre a raison non la foule insoumise

qui clochard devenant jetait ses oripeaux

un frère même bas est la part indécise

que les parents féconds offrent aux purs berceaux

Le généalogiste observe leur bouillotte

gratter le parchemin deviendra sa marotte

il voudra retrouver le germe adultérin

Barde que tu me plais toujours tu soliloques

tu me stupéfies plus que tous les ventriloques

le métromane à force incarne le devin. (QUENEAU, 1961, s/p)

Bastante semelhante ao anterior, mas mesmo assim diferente, como quaisquer irmãos gêmeos, este é o soneto formado a partir da troca do primeiro verso da segunda estrofe e de todo o último terceto, substituindo-se a sétima opção dessas pilhas de filetes pela oitava. Para ficar mais claro, pode-se observar essa nova combinação dentro da matriz matemática da máquina, de modo que alguns 0 's foram trocados por 1 e vice-versa, sinalizando que determinados versos deixaram de ser usados no novo soneto, e outros foram colocados em seu lugar, nas linhas 5, 12, 13 e 14 . 


$$
\mathbf{Q}^{\prime}=\left(\begin{array}{llllllllll}
0 & 0 & 0 & 0 & 0 & 0 & 1 & 0 & 0 & 0 \\
0 & 0 & 0 & 0 & 0 & 0 & 1 & 0 & 0 & 0 \\
0 & 0 & 0 & 0 & 0 & 0 & 1 & 0 & 0 & 0 \\
0 & 0 & 0 & 0 & 0 & 0 & 1 & 0 & 0 & 0 \\
0 & 0 & 0 & 0 & 0 & 0 & 0 & 1 & 0 & 0 \\
0 & 0 & 0 & 0 & 0 & 0 & 1 & 0 & 0 & 0 \\
0 & 0 & 0 & 0 & 0 & 0 & 1 & 0 & 0 & 0 \\
0 & 0 & 0 & 0 & 0 & 0 & 1 & 0 & 0 & 0 \\
0 & 0 & 0 & 0 & 0 & 0 & 1 & 0 & 0 & 0 \\
0 & 0 & 0 & 0 & 0 & 0 & 1 & 0 & 0 & 0 \\
0 & 0 & 0 & 0 & 0 & 0 & 1 & 0 & 0 & 0 \\
0 & 0 & 0 & 0 & 0 & 0 & 0 & 1 & 0 & 0 \\
0 & 0 & 0 & 0 & 0 & 0 & 0 & 1 & 0 & 0 \\
0 & 0 & 0 & 0 & 0 & 0 & 0 & 1 & 0 & 0
\end{array}\right)
$$

Substituindo o verso "Et pourtant c'était lui le frère de feintise" por "L'un et l'autre a raison non la foule insoumise", troca-se mais um simulacro, uma cópia, um reflexo catóptrico dos sonetos, como frère de feintise, por outro, igualmente gêmeo, igualmente reiterado, igualmente variado. Cada um desses sonetos, na superfície cheia de escaras, cicatrizes dos picotes da tesoura ou dentes das engrenagens mecânicas, tem sua própria razão, seu próprio todo, sua particularidade. Como unidade completa e autônoma, sintática e semanticamente, destaca-se da foule insoumise, da massa de poemas que espera a chance de ser rompida no cordão umbilical e nascer, insurgindo-se contra a própria máquina criadora.

Como o livro que suplanta o autor, produzindo poemas que ele próprio desconhece, os sonetos insoumis geram-se mesmo contra a vontade do leitor, que tem dificuldades de segurar tantos filetes de uma vez só com as mãos. Na impossibilidade de suster tantas rodas dentadas com os dedos, alguns filetes escapam, dando origem a outro texto, soneto que grita para nascer e o faz por vontade própria, que o livro-máquina desempenha como autômato.

Quanto a essa autonomia da máquina que, infensa à vontade do leitor, produz outros poemas por "falha" na operação, são iluminadores os versos do último terceto do segundo soneto anteriormente citado. "Barde que tu me plais toujours tu soliloques/tu me stupéfies plus que tous les ventriloques" é o próprio livro, bardo autômato que soliloquiza, versejando a despeito da vontade do leitor, por entre cujos dedos escapam suas engrenagens-filete, tão difíceis de manipular por mãos inábeis. 
De voz própria, é ao livro em si que se atribuem os sonetos, e não ao autor que desconhecia a imensa maioria dos produtos de sua máquina. Queneau, então, seria apenas um ventríloquo, que projetaria sua voz em alguns poemas, alheios a seu corpo, enquanto Cent mille milliards de poèmes, o verdadeiro bardo, estupefaz o leitor com sua multiplicidade, ou virtual infinidade, de sonetos emergentes do código-máquina.

Ainda na condição de máquina combinatória e mãe dos diversos sonetos gêmeos, o livro é un métromane, palavra que cintila entre os semas de útero (do grego metro) e de métrica. Útero maníaco, dando à luz os $10^{14}$ sonetos, por meio dos traumáticos cortes, este também é maníaco pela metrificação, pela versificação, pela forma fixa do alexandrino, que se impõe como ritmo de rotação das engrenagens de papel.

Como é ao louco, nas mais diversas mitologias, que cabe o papel do profeta, aquele que diz o que os outros não podem entender ou ver, le métromane à force incarne le devin: a combinatória maníaca de versos ganha ares de vaticínio, capacidade de leitura do futuro em uma semiótica de permutas e arranjos.

Destaca-se aqui a dialética entre possibilidade e probabilidade que rege o universo da combinatória, como possibilidade de conhecimento do que é e do que pode vir a ser. Afinal, é também como possibilidade que a poética das máquinas de Queneau se desvela, na medida em que se trata de uma literatura emergente do código: potência de combinações que a língua enseja e que devém ato na escrita. Seja nos recontos maquínicos de Exercícios de Estilo, seja nas recombinações aleatórias de Cent Mille Milliards de Poèmes, a literatura se constrói como acontecimento e contingência, resultado de procedimentos formais infensos à intenção autoral, os quais são condicionados pelas próprias regras de associação e seleção do código. Novas "máquinas de escrever", destes livros emerge sempre um texto inesperado, produzido pelas engrenagens da língua e da literatura.

\section{Considerações finais}

Na fronteira entre o livro e a máquina, os artefatos literários de Raymond Queneau se apresentam como materialização do programa estruturalista de que o texto é sempre produto da própria imanência da linguagem, e não de um sujeito a priori. Mais de meio século depois da produção de Exercícios de Estilo e Cent Mille Milliards de Poèmes, sua discussão permanece atual, especialmente ao considerar o contexto social, político e tecnológico da atualidade, em que um paradigma pós-humano parece raiar no horizonte.

De textos maquínicos, calcados em uma engenharia da linguagem, a literatura oulipiana e, especialmente, os livros de Raymond Queneau, postulam escrita como puro prazer, encenação, fabulação e atividade mecânica, que faz rir ou gozar como 
semblant da única coisa que realmente há: desvario do sujeito que não se percebe também como produto da significação e do código.

Escrita enquanto ato, processo mais do que produto, é só como linguagem que existem o sentido e o texto nas produções do Oulipo. Produzido pelo verbo, e não pelo sujeito, o texto de Raymond Queneau lembra-nos que apenas na linguagem o sujeito emerge, como mais um texto, tal qual o literário. Sem anterioridade ou posteridade, metafísica da presença ou teleologia da escrita, uma poética emergente do código é a própria linguagem que faz falar e cria, não só o universo da obra, mas também o sujeito empírico que a lê ou escreve. Experiência máxima da dessubjetivação, trata-se sempre aqui de um texto que se diz, em vez de querer dizer algo a alguém. Código, e não mensagem; engrenagem, e não inspiração: eis-nos nos diante de uma cadeia de significantes que gira como uma esteira de montagem.

Abstract
One of the central discussions in Literary Theory,
irrespective of the theoretical branch, deals with
what the literary phenomenon consists of: Autho-
rial intention? Reader interpretation? Collective
construction of meaning? These, among many
other possible explanations, define literature as a
discursive practice by empirical subjects. But the-
se explanations may be questioned in a political,
social and technological context that gradually
defines itself as "post-human". In this context, a
poetics that comes from language itself, as a po-
tency that becomes an act through writing - here
understood as an intransitive event - is not only
a theoretical alternative, but also a practical one,
especially in the literary practice of authors from
the French group Oulipo (Ouvroir de Litterature
Potentielle). By facing this stalemate - literature
that comes from the code, not from an empirical
subject-we analyze herein Raymond Queneau's
writings, which can be understood more as lite-
rary machines than as literary works. Among
his texts, we highlight Exercícios de estilo and Cent mille milliards de poèmes, which call our attention because they erase all possible referentiality. These texts work by means of finely engineered formal gears, endowed with an intransitive meaning, which points to the code that oils the linguistic gears and makes the wheels turn.

Keywords: Oulipo; Raymond Queneau; literary machines; poetics of the code. 


\section{REFERÊNCIAS}

BORGES, J. L. Obras completas I. Buenos Aires: Emecé, 1989.

CUDDON, J. A. B. Dictionary of Literary Terms and Literary Theory. Cambridge: Penguin, 1998.

DELEUZE, G.; GUATTARI, F. O antiédipo. São Paulo: Editora 34, 2010.

DERRIDA, J. Força e significação. In: . A escritura e a diferença. São Paulo: Perspectiva, 2009.

. Papel-máquina. Rio de Janeiro: Estação Liberdade, 2004.

FREUD, S. O estranho. Edição standard brasileira das obras psicológicas completas de Sigmund Freud. Volume XVII. Rio de Janeiro: Imago, 1969.

LACAN, J. Le Séminaire, tome 11: Les Quatre Concepts fondamentaux de la psychanalyse. Paris: Seuil, 1964.

MAN, Paul de. Alegorias da leitura: a linguagem figurada em Rousseau, Nietzsche, Rilke e Proust. Rio de Janeiro: Imago, 1996.

QUENEAU, R. Cent mille milliards de poèmes. Paris: Gallimard, 1961. Exercícios de estilo. Trad. Luiz Rezende. Rio de Janeiro: Imago, 1995.

SAUSSURE, F. Curso de linguística geral. São Paulo: Cultrix, 1970. SILVA, J. J. Filosofias da matemática. São Paulo: Fapesp, 2007. 